\title{
RESEARCH
}

\section{The Similarity Between the Perception and Interpretation of Information in a Profane and a Religious Context}

\author{
Guido Peeters and Ann Hendrickx \\ Laboratory of Experimental Social Psychology \\ Catholic University of Leuven, Belgium
}

\begin{abstract}
On the basis of descriptions of hypothetical patients, participants provided similarity ratings regarding 1 of the following issues: (a) the patients' religious attitudes, (b) religious doctrines in which the patients adhered, (c) their personalities, and (d) the nature of the (chemical) medicines the patients were taking. Patterns of (dis)similarities produced by participants were compared with theoretical patterns diagnosing 2 complementary modes of thinking or cognitive programs: (a) The Self-Other (SO) Program, which is related to correspondent inference theory, generates a personalized discourse, and shapes reasoning about personality; and (b) the Third-Person (3P) Program, which is related to the analysis of variance model of causal attribution, generates a depersonalized discourse, and shapes reasoning in natural sciences. Consistently, inferences regarding personalities and medicines reflected the SO and $3 \mathrm{P}$ programs, respectively. Like personality inferences, inferences concerning religion also reflected the SO program, however, only if religion was presented as an attitude. Inferences about religion as a doctrine reflected the $3 \mathrm{P}$ program and resembled inferences about medicines rather than inferences about personality. Although participants were probably able to think in terms of complementarity, combined use of the SO and 3P programs was exceptional.
\end{abstract}

Requests for reprints should be sent to Guido Peeters, Laboratory of Experimental Social Psychology, Tiensestraat 102, B-3000 Leuven, Belgium. E-mail: guido.peeters@ psy.kuleuven.ac.be 
This article deals with two related questions: (a) Given that in everyday life persons use person-related or object-related reasoning, does the same hold for reasoning about religion? (b) If so, are the related reasoning schemes used throughout, or are specific reasoning schemes used when dealing with religion? Answers to these questions may depend on what is meant by person- and object-related reasoning. Philosophers (e.g., Buber, 1923) and linguists (e.g., Benveniste, 1966) have distinguished between person and nonperson (object) by associating the former with pronominal categories of the first and second person (I and thou) and the latter with the third person (he, she, it). This distinction does not match that between human and nonhuman nor that between mind and matter. Any object can be dealt with in both the I-thou mode and the third-person mode. The difference does not reside in the nature of the objects but in the way they are experienced. Buber (1923) elaborated the phenomenology of this experience. He related the I-Thou versus third-person distinction to the possibility to deal with an object as either a being one can encounter or an instrument one can use. Peeters $(1983,1989)$ demonstrated that the distinction in question was also associated with formal aspects of human information processing. They were mapped in a formal model referred to as the relation pattern model (RPM).

\section{THE RPM}

The RPM is a model of social cognition derived from linguistic universals. For theoretical foundations and connections with linguistics and with Buber's philosophy, the reader is referred to Peeters $(1983,1989)$ and Hendrickx and Peeters (1997). One assumption of the RPM is that the cognitive system processes social information in terms of relationships between persons. Cognitive constructs involving persons and relationships form "relational patterns." In Table 1, eight relational patterns are presented. They involve two persons, A and B, and various combinations of positive "helping" relationships and negative "not helping" relationships. Another assumption of the model is that perceived (dis)similarities between persons reflect formal (dis)similarities straightforwardly implied by the relationships. The point is that these (dis)similarities vary in a manner depending on the way the relations are conceived: either as relations with self and other or as relations with particular individuals such as "person A" and "person B." In the RPM terminology, these ways of conceiving relational information are referred to as cognitive programs, respectively, the Self-Other (SO) program and the Third Person (3P) program.

Table 1 displays similarities (1) and dissimilarities (0) associated with the SO program (column $\mathrm{SO}$ ) and two variants of the $3 \mathrm{P}$ program (columns $3 \mathrm{P}_{1}$ and $3 \mathrm{P}_{2}$ ). For instance, in relational Pattern 4, A and B are similar (1) according to the SO program but dissimilar (0) according to the $3 \mathrm{P}$ program. Specifically, they are similar in that either of them helps only himself/herself without helping the other, and they are dissimilar in that they provide help to different persons $\left(3 \mathrm{P}_{2}\right)$ and receive help from 
TABLE 1

Similarities (1) and Dissimilarities (0) Implied by Eight Relational Patterns as a Function of the SO Program (SO) and Two Equivalent Variants of the $3 \mathrm{P}$ Program $\left(3 \mathrm{P}_{1}\right.$ and $\left.3 \mathrm{P}_{2}\right)$

\begin{tabular}{llll}
\hline & & Program \\
\cline { 2 - 3 } Relational Patterns & $S O$ & $3 P_{1}$ & $3 P_{2}$ \\
\hline 1 (a) A and B help each other and themselves & & 1 & 1 \\
2 (p) A and B help neither each other nor themselves & 1 & 1 & 1 \\
3 (d) A and B help each other, not themselves & 1 & 0 & 0 \\
4 (m) A and B help themselves, not each other & 1 & 0 \\
5 (f) A helps B and himself/herself; B helps neither A nor himself/herself & 0 & 1 & 0 \\
6 (k) B helps A and himself/herself; A helps neither B nor himself/herself & 0 & 1 & 0 \\
7 (g) A helps B, not himself/herself; B helps himself/herself, not A & 0 & 0 & 1 \\
8 (j) B helps A, not himself/herself, A helps himself/herself, not B & 0 & 0 & 1 \\
\hline
\end{tabular}

Note. Letter marks between brackets $(\mathrm{a}, \mathrm{b}, \ldots \mathrm{j})$ are identification letters that have been used consistently across previous studies to designate the relational patterns in formal mathematical elaborations of the relation pattern model (Peeters, 1983, 1987, 1991; Peeters \& De Wit, 1995; and Peeters \& Hendrickx, 1998).

different persons $\left(3 \mathrm{P}_{1}\right)$. In this way, using the $\mathrm{SO}$ program, one may consider that $\mathrm{A}$ and $\mathrm{B}$ share particular personality traits such as self-reliance and self-regard. However, using the 3P program, one may consider that $\mathrm{A}$ and $\mathrm{B}$ face different troubles (e.g., different diseases) and have the disposal of different resources to cope with them (e.g., different medicines). In an analogous way, perceivers presented with relational Pattern 5 may consider that $\mathrm{A}$ is more self-reliant and generous than $\mathrm{B}(\mathrm{SO})$. However, they may consider also that A and B suffer from the same disease $\left(3 \mathrm{P}_{1}\right)$, whereas only A has the disposal of appropriate medicines $\left(3 \mathrm{P}_{2}\right)$.

The degree to which a subject uses $\mathrm{SO}$ and $3 \mathrm{P}$ programs when drawing inferences is measured by computing correlations $r$ between the (dis)similarity ratings provided by the subject across the eight relational patterns and the (dis)similarity values displayed in Table 1. Positive correlations with columns in Table 1 are proportional to the amount of variance accounted for by the cognitive programs indicated in the column heads.

\section{THE ROLE OF THE SO AND 3P PROGRAMS IN THE PROCESSING OF SOCIAL INFORMATION}

Extensive research, reviewed by Hendrickx and Peeters (1997) and Peeters and Hendrickx (1998), has led to the following conclusions. First, social perceptions seem biased to the SO program. Often perceivers who use the SO program are un- 
aware of obvious alternative views that could be generated using the $3 \mathrm{P}$ program. This bias is prominent in the processing of value-laden information such as information about feelings and acts with good or bad consequences. Less value-laden information (about ages, body sizes, etc.) is processed more by the 3P program (Hendrickx \& Peeters, 1997). Second, from the first studies (Peeters, 1983, 1991), it was evident that the SO program generates discourses that can be characterized as personalized. They involve interpretive categories such as personality traits and social motives that are readily experienced as manifestations of the inner life of a person. Alternatively, the 3P program tends to generate discourses that remind one of the natural sciences and can be characterized as depersonalized. In this way, the SO and $3 \mathrm{P}$ programs generate alternative interpretations that fit Oser and Reich's (1987) definition of complementarity: They have a common reference (e.g., the observation that A and B help themselves and do not help each other), and they are individually complete explanations that belong to distinct conceptual frameworks (e.g., an explanation in terms of personality and an alternative explanation in terms of diseases and medicines).

The duality of SO and 3P programs is paralleled by two main theories of causal attribution, respectively, correspondent inference theory (Jones \& Davis, 1965) and the analysis of variance (ANOVA) model (Kelley, 1967).

First, inferences mediated by the SO program and correspondent inferences are similar in character: Both concern personalized contents such as personality traits and other stable personal dispositions. In addition, just as perceivers are biased to use the SO-program rather than the $3 \mathrm{P}$ program, perceivers are also biased to explain behavior relying on correspondent inferences rather than on situational causes. Actually, this "correspondence bias" (Jones, 1990) or "fundamental attribution error" (Ross, 1977) is one of the most pervasive biases reported in the social psychological literature. Finally, stressing the constructive role of the self-other distinction, the SO program may fill a gap in correspondent inference theory. Jones and Davis (1965) assumed that perceived actions elicited correspondent inferences if the actions had positive or negative consequences for the perceiver (hedonic relevance hypothesis). According to the SO program, it would not be the consequences for the perceiver as such that matter, but the differential consequences for the actor himself/herself and the other who is the target of the action. In this way, the perceiver may perceive a person who helps as helpful only if that person helps another person and not if he/she helps only himself/herself. Thereby, it would not matter whether the perceiver identifies with the actor or with the person who enjoys the help.

Although the SO program relates to correspondent inference theory, the two variants of the 3P program, displayed in Table 1, match two parameters of Kelley's (1967) classic ANOVA model of attribution: distinctiveness and consensus. Similarities and dissimilarities implied by $3 \mathrm{P}_{1}$ reflect respectively low and high distinctiveness. For instance, A and B are conceived as dissimilar if they can be 
distinguished from each other on the basis of information telling who is helping A and who is helping B. In an analogous way, similarities and dissimilarities implied by $3 \mathrm{P}_{2}$ reflect, respectively, high and low consensus. For instance, $\mathrm{A}$ and $\mathrm{B}$ are conceived as similar if they agree on who they help and who they do not help. In this study, the distinction between $3 \mathrm{P}_{1}$ and $3 \mathrm{P}_{2}$ has only methodological relevance, the theoretically relevant distinction being that between the $\mathrm{SO}$ and $3 \mathrm{P}$ programs.

\section{SO AND 3P PROGRAMS IN REASONING ABOUT RELIGION}

It seems evident that religion is associated with personalism, and thinking about A's and B's religious convictions resembles more thinking about personality than thinking about impersonal attributes. Like personality, religion may be one of the value-laden issues that tend to be processed by the SO program. However, it was demonstrated that value-laden issues are perfectly suited to be processed by the $3 \mathrm{P}$ program as well (Peeters, 1983). Moreover, reasoning about certain value-laden issues, especially justice principles, was found to be processed exclusively by the $3 \mathrm{P}$ program (Peeters, 1987). Hence, it is feasible that the concept of religion is connected with a 3P-shaped discourse. One possibility is that the concept of religion is connected with alternative SO- and 3P-shaped discourses. Considering that religion can be conceived either as a personal attitude or as a doctrine, an appealing hypothesis may be that reasoning about religion is shaped by the SO program if it is conceived as an attitude and by the $3 \mathrm{P}$ program if it is conceived as a doctrine. This hypothesis was tested in the following experiment.

\section{METHOD}

\section{Participants}

Sixty-four male and 203 female Dutch-speaking introductory psychology students (ages 18-19) agreed to complete an anonymous questionnaire. Each participant was randomly assigned to one out of four conditions.

\section{Conditions}

In all conditions, participants provided similarity ratings regarding two hypothetical patients (A and B) across a set of items that were presented in a random order and that corresponded to the eight relational patterns in Table 1. However, in the items, the relational information was not implemented with the verbs helping and 
not helping but with other descriptions of ways in which beneficial effects were produced or failed to be produced.

In two experimental conditions, helping and not helping were replaced with presence and absence of beneficial effects exerted by $\mathrm{A}$ and $\mathrm{B}$ on each other and themselves through religion. In one of these conditions, called attitude condition, religion was presented as a personal attitude. In the other condition, called doctrine condition, religion was presented as a doctrine. Similarity ratings were obtained concerning the participants' impressions of A's and B's religious convictions. In two control conditions, similarity ratings were obtained concerning profane issues that reflected the attribution theorist's distinction between personal dispositions and situational causes and that were assumed to be selectively associated with the SO and 3P programs. Specifically, in the personality condition, the beneficial effects were attributed to personality instead of religion and similarity ratings concerned A's and B's personalities. In the medicine condition, the effects were attributed to (chemical) Medicines A and B had taken and similarity ratings concerned the chemical composition of the medicines.

\section{Questionnaires}

In an introductory paragraph, participants were informed that each item provided a description of two hypothetical patients in a hospital room who were severely ill. Questionnaires varied across conditions, as described later in this article. ${ }^{1}$

In the attitude condition, the patients were presented as religious people who rely on religious attitudes to find help and comfort for themselves, as well as to give help and comfort to each other. Religious attitudes were specified as ways of experiencing a relationship with the divine reality. ${ }^{2}$ Further information concerned the degrees to which the patients' religious attitudes were sources of help and comfort. This information varied across items consistent with the relational patterns in Table 1. Specifically helping/not helping relationships were implemented with "being able/unable to provide help and comfort to" (e.g., Item 3: "Neither patient draws any help or comfort from the way he or she experiences his/her relationship with the Divine. However, relying on that experience the patients can be a great help and comfort to each other"). For each item, the participants rated the degree of

\footnotetext{
${ }^{1}$ Notice that only Item 3 (regarding relational pattern 3 ) is presented. Other items can be extrapolated on the basis of the input configurations in Table 1. English translation of complete questionnaires is available from the author.

${ }^{2}$ The expression "divine reality" is a tentative translation of the Dutch term het goddelijke, which is currently used to refer to the ultimate reality in a rather general and impersonal way. Thus, there was no explicit reference to a personal God in any condition.
} 
similarity that they expected between the patients' religious attitudes using a scale ranging from 0 (totally different) to 9 (very similar).

The doctrine condition differed from the attitude condition in that philosophical or religious doctrine was substituted for religious attitude and the specification of religion as the experience of a relationship with the divine was omitted (e.g., Item 3: "Neither of the patients can draw any help or comfort from his/her own doctrine, but they draw help and comfort from each other's doctrines"). The object of the similarity ratings was defined as the patients' religious doctrines (instead of religious attitudes).

In the personality condition, the patients were presented as people who try to find in themselves the strength needed to hold out and who try also to help each other. The formulation of the items was slightly adjusted to fit the new context. In this way, the expressions translated as "comforting oneself" and "comforting the other" were replaced with expressions translated, respectively, as "finding in oneself the strength needed to hold out" and "being a help to the other" (e.g., Item 3: "The patients do not draw from themselves the strength needed to hold out. However, they are a great help and comfort to each other"). The object of the similarity ratings was defined as the patients' personalities.

In the medicine condition, it was explained that each patient got a carton of pills and that they tried out not only their own pills but also each others'. The formulation of the items was adjusted to fit the new context. In this way, the expressions in terms of "comforting" (vs. "not comforting") oneself and/or the other were replaced with expressions telling that patients felt "better" (vs. "worse") when taking a pill from their own or the other's carton (e.g., Item 3: "The patients feel worse after a pill from their own carton. However, they feel better after a pill from the other's carton"). The object of the similarity ratings was defined as the nature of either patient's pills.

In principle eight items were required: one for each relational pattern in Table 1. However, it is evident from Table 1 that the only difference between Patterns 5 and 6 is that the Labels A and B are interchanged. It follows that if no labels are used and persons are only presented as "two patients," the Patterns 5 and 6 can be implemented by the same item telling, for instance, that one patient's religious attitude is a source of help and comfort to him/herself and to the other patient, whereas the other patient's religious attitude is not a source of help and comfort, neither to himself/herself nor to the other. The same remark applies to Patterns 7 and 8 . Hence, participants were presented with only six instead of eight items. However, computations were based on similarity ratings for all eight of the relational configurations whereby the similarity score obtained for Pattern 5 was used also for Pattern 6, and the score obtained for Pattern 7 was used also for Pattern 8. Concretely, this means that two items weighed double. In this way, product moment correlations of the similarity ratings with the similarity values presented in Table 1 were proportional to the amounts of variance accounted for by the SO program and the two variants 
of the 3P program without having any overlap between variances accounted for by different programs. Peeters and Hendrickx (1998) shared more information and evidence about the validity of this procedure.

\section{RESULTS}

For each participant, $r$ was computed between the participant's similarity ratings and the similarity values displayed in Table 1. Any absolute $r$ of .50 was classified as "outstanding." "3 Eighty percent of the participants produced at least one positive outstanding $r$, whereas less than $8 \%$ produced one or more negative ones. Considering that the RPM predicted positive $r$ 's and no more positive than negative $r$ 's are expected by chance, the data strongly argue for the validity of the RPM as a whole.

Proportions of participants who responded in accordance with the SO and 3P program, and $\chi^{2}$ tests $^{4}$ of differences between conditions are presented in Tables 2 and 3 , respectively. The distinction between variants of the $3 \mathrm{P}$ program being not a central issue, outcomes presented for the 3P program were not subdivided further into outcomes for $3 \mathrm{P}_{1}$ and $3 \mathrm{P}_{2}$. Let it just be mentioned that 61 out of 90 participants who produced outstanding $r$ 's consistent with the $3 \mathrm{P}$ program only did so by producing an outstanding $r$ consistent with $3 \mathrm{P}_{2}$ only. This means that participants who stuck to the $3 \mathrm{P}$ program focused more on (dis)similarities defined in terms of distinctiveness than on (dis)similarities defined in terms of consensus.

As one could expect, reasoning about personality was dominated by the SO program and reasoning about chemical medicines by the $3 \mathrm{P}$ program. For the religious conditions, the results contradicted the idea that reasoning about religion would only resemble reasoning about personality. As it was hypothesized, reasoning about religion as an attitude resembled reasoning about personality, indeed, but reasoning about religion as a doctrine resembled reasoning about chemical medicines. Thus, the data did not contrast between profane and religious conditions. Rather, they suggested a contrast between SO-related personalized conditions (personality and attitude) versus 3P-related depersonalized conditions (medicine and doctrine) ${ }^{5}$

\footnotetext{
${ }^{3}$ The threshold of $r=.50$ was used in previous analyses (Peeters, 1991) and is assumed by statisticians to represent a large-sized effect.

${ }^{4}$ It was ascertained that the contribution made to $\chi^{2}$ by few cells with expected frequencies of smaller than five was negligibly small.

${ }^{5}$ It could be objected that the observed effects were due to uncontrolled irrelevant factors that covaried with the conditions. To check the plausibility of this objection, seven judges (advanced psychology students and young graduates) were asked to make comparisons between analogous items (i.e., items representing the same relational pattern) from different conditions. The judges' task was not to draw inferences about the patients but to rate on 10-point scales the degree to which the information
} 
TABLE 2

Proportions of Participants Who Produced Outstanding Positive Correlations Consistent With Either the SO Program Only, or the 3P Program Only, or Both the SO and the 3P

Programs or With Neither the SO Nor the 3P Programs

\begin{tabular}{lccccc}
\hline & \multicolumn{2}{c}{ Religious Conditions } & & \multicolumn{2}{c}{ Profane Conditions $^{n}$} \\
\cline { 2 - 3 } \cline { 5 - 6 } & Attitude $^{\mathrm{a}}$ & Doctrine $^{\mathrm{b}}$ & & Personality $^{\mathrm{b}}$ & Medicine $^{\mathrm{c}}$ \\
\hline SO program only & .57 & .18 & & .74 & .11 \\
3P program only & .16 & .47 & & .05 & .69 \\
SO and 3P & .01 & .12 & & .03 & .08 \\
Neither SO nor 3P & .26 & .23 & & .18 & .12 \\
\hline
\end{tabular}

Note. $\mathrm{SO}=$ Self-Other; $3 \mathrm{P}=$ Third-Person. Participants were classified as "SO Program only" if they produced only an outstanding positive $r$ with the (dis)similarity values in the column SO (Table 2). Participants were classified as "3P Program only" if they produced only outstanding $r$ 's with (dis)similarity values of at least one of the 3P columns. "SO and 3P" means that outstanding $r$ 's were produced simultaneously with the (dis)similarity values in the SO column and at least one of the $3 \mathrm{P}$ columns. Participants without any outstanding $r$ 's were classified as "Neither SO nor 3P."

${ }^{\mathrm{a}} n=70 .{ }^{\mathrm{b}} n=66 .{ }^{\mathrm{c}} n=65$.

TABLE 3

Chi-square Values for Differences Between Conditions $(d f=3)$

\begin{tabular}{lccc}
\hline & Medicine & Personality & Doctrine \\
\hline Attitude & $50.21^{*}$ & 6.90 & $30.23^{*}$ \\
Doctrine & 6.71 & $49.43^{*}$ & \\
Personality & $70.33^{*}$ & & \\
\hline
\end{tabular}

$* p<0.00001$

\section{DISCUSSION}

It can be concluded that if person- and object-related reasonings are defined in terms of the $\mathrm{SO}$ and $3 \mathrm{P}$ programs, the answers to the questions raised in the initial paragraph are affirmative: (a) Both ways of reasoning can be traced in thinking

communicated about the patients differed between the two items. Difference ratings combined across judges were quite reliable (Cronbach's $\alpha=0.78$ ). The differences did not replicate the present contrast obtained between personalized conditions (attitude and personality) and depersonalized conditions (doctrine and medicine). Rather, judges tended to contrast, although not significantly, religious against profane conditions. This means that the significant differences observed between personalized and depersonalized conditions did not reflect some accidental irrelevant features of the items, but were effectively due to the inferences drawn from the relational information. 
about religion. In this respect, thinking about religion differs from thinking about personality that in previous studies (Peeters, 1983, 1991) was found to be unilaterally bound to the person-related form of reasoning; and (b) the same formal reasoning schemes are used throughout religious and profane issues.

In the introductory section, these reasoning schemes were related to different theories of causal attribution. It is to be taken into account, however, that attribution theory basically deals with the question of which causes are inferred when particular effects are given. For instance, attribution theorists may observe that perceivers are inclined to explain events (A helps B) as effects of personal dispositions (A may be helpful) rather than of situational factors (A may be rewarded). In this study, however, not only the effect (A helps and comforts B) was given but also the cause, which was a personal disposition (A's personality) in the personality condition and a situational factor (A's medicine) in the medicine condition. The question at stake was not whether perceivers are inclined to infer one cause rather than the other, but whether these inferences involve different reasoning schemes reflecting the cognitive SO and 3P programs. The results did not only confirm that inferences of personal dispositions and situational factors are underlain by different reasoning schemes reflecting, respectively, the SO and 3P programs. They showed also that these reasoning schemes differentiate between two ways of thinking about religion that are connected with two current concepts of religion. Specifically, when religion is presented as an attitude, it activates the reasoning scheme of the SO program that is connected with thinking about personality and the personalistic thinking dealt with by the correspondent inference theory of causal attribution. When religion is presented as a doctrine, it activates the reasoning scheme of the 3P program that is connected with apparent scientific thinking, such as about the efficacy of medicines, and with the way of thinking described by the ANOVA model of causal attribution.

It was explained previously that SO- and 3P-generated interpretations are complementary. Oser and Reich (1987) observed that at the age of our participants, the ability to think in terms of complementarity has developed sufficiently to accept the validity of alternative interpretations without rejecting one as false. They also found that this development was independent of knowledge domains (science, religion, etc.). Hence, participants could be expected to derive similarities using both the $\mathrm{SO}$ program and $3 \mathrm{P}$ program and to base overall similarity ratings on additive combinations of the SO- and 3P-related similarities. This would have resulted in outstanding positive $r$ 's for both the $\mathrm{SO}$ program and the $3 \mathrm{P}$ program. However, as it is shown in Table 2 (row "SO and 3P"), these pairs of outstanding positive $r$ 's were exceptional. A possible explanation could be that $\mathrm{SO}$ and $3 \mathrm{P}$ programs were combined in complex nonadditive ways belonging to the higher levels of thinking in terms of complementarity described by Oser and Reich (1987). Peeters (1991) described complex ways of combining the SO and 3P programs. They resulted in outstanding negative $r$ 's with the outputs of the RPM. Their occurrence was prom- 
inent in psychoanalytic thinking (Peeters \& De Wit, 1995). However, in this study, negative $r$ 's were rather exceptional. Apparently, participants used a single cognitive program at once. This means that the distinction between religion as an attitude and religion as a doctrine is not merely academic, but represents the top of an iceberg of dual knowledge organization. Reasoning schemes involved in thinking about religion as an attitude seem formally unrelated to the reasoning schemes involved in thinking about religion as a doctrine. Hence, one issue future research may deal with concerns the conditions in which people may combine SO and $3 \mathrm{P}$ programs in reasoning about religion integrating the attitude and doctrine aspects as complementary sides of the same coin. Generalizing from observations regarding clinical psychological thinking (Peeters \& De Wit), a main factor may be the availability of conceptual frameworks in which SO-related and 3P-related concepts are integrated.

Another aim of future research may concern the relationship of the present duality with other dualities such as intrinsic and extrinsic religious orientations (Allport \& Ross, 1967). A starting point may be provided by Kirkpatrick and Hood's (1990) conclusion that the extrinsic orientation implies an "utilitarian" conception of religion that is reminiscent of the $3 \mathrm{P}$ program.

\section{ACKNOWLEDGMENTS}

An extended report—including additional background information, an alternative data analysis (leading to the same conclusion), and an English translation of the four questionnaires - can be requested from the first author and is preferentially forwarded by e-mail (as an ASCII file).

We acknowledge the support of the Fund for Scientific Research (FWO) Flanders, to which the first author was attached as a senior research associate and which accorded a research assistantship to the second author. We acknowledge also the support provided by the Catholic University of Leuven by according a post-doctoral research fellowship to the second author.

\section{REFERENCES}

Allport, G. W., \& Ross, J. M. (1967). Personal religious orientation and prejudice. Journal of Personality and Social Psychology, 5, 432-443.

Benveniste, E. (1966). Problèmes de linguistique générale [Problems of general linquistics]. Paris: Gallimard.

Buber, M. (1923). Ich und $D u$ [I and thou]. Leipzig, Germany: Insel.

Hendrickx, A., \& Peeters, G. (1997). A psycholinguistic paradigm of dual information processing in social cognition. Psychologica Belgica, 37, 205-218.

Jones, E. E. (1990). Interpersonal perception. New York: Freeman. 
Jones, E. E., \& Davis, K. E. (1965). From acts to dispositions: The attribution process in person perception. In L. Berkowitz (Ed.), Advances in experimental social psychology (Vol. 2, pp. 219-266). New York: Academic.

Kelley, H. H. (1967). Attribution theory in social psychology. In D. Levine (Ed.), Nebraska symposium on motivation (Vol. 15, pp. 192-238). Lincoln: University of Nebraska Press.

Kirkpatrick, L. A., \& Hood, R. W., Jr., (1990). Intrinsic-extrinsic religious orientation: The boon or bane of contemporary psychology of religion? Journal for the Scientific Study of Religion, 29, 442-462.

Oser, F. K., \& Reich, K. H. (1987). The challenge of competing explanations: The development of thinking in terms of complementarity of "theories". Human Development, 30, 178-186.

Peeters, G. (1983). Relational and informational patterns in social cognition. In W. Doise \& S. Moscovici (Eds.), Current issues in European social psychology (pp. 201-237). Cambridge, England: Cambridge University Press.

Peeters, G. (1987). The Benny Hill Effect: Switching cognitive programmes underlying subjective estimations of the outcomes of bargains concerning distributions of rewards. European Journal of Social Psychology, 17, 465-481.

Peeters, G. (1989). Person and non-person as basic concepts underlying alternative discourses about reality: An analysis based on the social-psychological relation-pattern model and Greimas' semiotic square. Ultimate Reality and Meaning. Interdisciplinary Studies in the Philosophy of Understanding, 12, 113-132.

Peeters, G. (1991). Relational information processing and the implicit personality concept. Cahiers de Psychologie Cognitive-European Bulletin of Cognitive Psychology, 11, 259-278.

Peeters, G., \& De Wit, R. (1995). Self-other and third-person anchored modes of thinking in psychological expertise: Cognitive concomitants of behaviourist, client-centered, and psychoanalytic concepts. International Journal of Psychology, 30, 317-328.

Peeters, G., \& Hendrickx, A. (1998). Alternative cognitive programs underlying self-other and other-other comparisons: An illustration with gender categorization. Revue Internationale de Psychologie Sociale, 11, 97-113.

Ross, L. (1977). The intuitive psychologist and his shortcomings. In L. Berkowitz (Ed.), Advances in experimental social psychology (Vol. 10, pp. 219-266). San Diego, CA: Academic. 
Copyright of International Journal for the Psychology of Religion is the property of Lawrence Erlbaum Associates and its content may not be copied or emailed to multiple sites or posted to a listserv without the copyright holder's express written permission. However, users may print, download, or email articles for individual use. 